\title{
Building Confidence in Employees with Dyslexia and other Neurodiverse Conditions: An Interview with Nicola James, CEO and Founder of Lexxic
}

\author{
Nicola James \\ CEO and Founder of Lexxic.com \\ London, UK \\ Jane Buggle \\ Deputy Librarian and Learner Supports Coordinator, Dublin Business School \\ Dublin, Ireland
}

(C) Nicola James and Jane Buggle. This work is licensed under the Creative Commons Attribution-NonCommercial-ShareAlike 4.0 International License. To view a copy of this license, visit https://creativecommons.org/licenses/by-nc-sa/4.0/ .

\section{Introduction}

I first met Nicola James when, at the invitation of a student, she ran a free workshop on Building Confidence in Students with Disabilities at Dublin Business School in February 2017. At this workshop, Nicola described her own experiences as a student with undiagnosed dyslexia, how she began to thrive academically after diagnosis and how this experience led to her founding Lexxic. Lexxic is a specialist consultancy that employs a team of psychologists to run workshops and interventions with neurodiverse employees within companies, providing them with strategies and techniques to build confidence in order to drive performance. Lexxic has now grown to a flourishing business whose clients include Deloitte, AXA Healthcare, the NHS, the UK Cabinet Office, and the General Medical Council, among many others. Lexxic recently launched the Neurotalent Unlocked online learning platform. Nicola has continued to deliver a free workshop in DBS annually.

Keywords: Educational Psychology; Occupational Psychology; Learning Disabilities;

Dyslexia

JB: What was your experience of the education system as a student who had undiagnosed dyslexia?

NJ: I did not know that I was dyslexic until I went to university and I was not diagnosed until towards the end of my degree programme. I always remember feeling that my value as a student was defined by my grade and, when I saw the amount of effort I would put in and that my grade did not reflect the effort I had put in, it gave me a sense that I was not as good as the students who managed to get an A with seemingly little effort. I remember comparing myself to the academic students, feeling that I would never be good enough. I also found that during my time in education in the UK there was a lot of emphasis on academic standards but not much focus on all the other gifts people have that fall outside the norm: having ideas, being creative, emotional intelligence. I felt the system, on reflection, overpraised linear thinkers. Yet 
running a business today, where when I started I recruited many psychologists who are more linear thinkers and manage academia much more naturally then myself, I started to realise that even though they were great at the detail and the linear thinking, they could not go into the clouds, think ten steps ahead and innovate like I do. It made me realise we need both linear and holistic brains as they really complement each other and, without all the neurodiverse people that work for me, we would have far less innovation and fresh ideas. I also worked with some Irish students who explained that only until a few years ago they would put on the academic grade certificate if you had extra help or not. This would have mortified me; this was not the same in the UK education system, but I think I would have felt stamped or labelled as someone different, someone not as good. I would be embarrassed and may never have even asked for extra time to avoid this happening.

JB: How did your experience of university change when you received your assessment of dyslexia?

NJ: When I was diagnosed with dyslexia in the third year of my degree, it felt like something just hit me in the face: that's why...now I understand. The reason I suspected I had dyslexia was when I wrote up an essay on the same subject I had presented on, and at the presentation I was given a lot of praise for understanding the subject in great detail, the same teacher said that I did not know what I was talking about in my essay. I actually knew so much on the subject, which was around psychology and mental health; I had read so much but I did not know how to get all my thoughts down on paper. For me the world of knowledge is like a mind map with lots of interconnecting parts and to get all this down in a linear 2000-word essay was impossible. I had never been taught how to write an essay in terms of structure, a beginning, a middle and an end. I just put my thoughts down. However, what I thought I was writing and what I actually wrote were sometimes two different things. So, when I received such contradictory feedback for work on the same topic, I got so upset. I burst into the lecturer's office and asked how dare she say I don't know what I am talking about and then I recited to her everything I knew, she looked speechless. Another lecturer came in and she turned out to be the disability support teacher. After a chat, I was then referred for a dyslexia assessment. I had already started to have an inkling that I could be dyslexic, but this just confirmed it. My dyslexia assessment made me relieved and angry at the same time, I understood but I was angry as to why I had not been diagnosed earlier, why no one had picked that up previously..... felt let down. However, when I got support during my Master's degree, where even though I needed a 2:1 to get on the course and initially got rejected via the electronic assessment process for the course, when I wrote a letter explaining my diagnosis and had a phone interview I was then accepted on the course. And this is where I met the amazing Margaret Herrington, OMG the amount of light bulb moments I had during my dyslexia support sessions with her was a revelation! What I started to realise is that, as a dyslexic individual, I did not implicitly see structure in books of essays but when she pointed these out and started to teach me about how to structure things, I had so many "Oh yeah, Oh I see" moments. This also worked with reading. Before delving into very specific books on one topic area related to an essay, I would read a book or paper that gave me an overview so that I would have the bigger picture, which was what my brain liked. Then I could delve into the different topics because I 
understood how they fitted together at the macro level. I still hated to read, I love audio books, but reading would involve lots of highlighting and rereading and crying when something just would not go in. The magic of the text-to-speech software changed my experience of this. Suddenly when reading off a screen, the words were highlighted as they were read out-loud by a voice, this gave me a visual colour imprint of a word as well as an auditory imprint. This changed my world. I no longer needed to proofread and check and then double-check and check again if what I had written is what I thought I had written. This technology created so much space for me and saved me so much time, my brain was starting to see that new ways of working were paying off. To be honest, at the end of my degree, I actually officially gave up and as soon as I gave up help seemed to appear. This technology reduced the rereading so much and my grades on my Master's started to increase to the extent that on my last essay, I got one point off a First. Margaret made such a difference to me and I would not be here today helping others if it were not for her help and persistence. She sometimes looked at me like I was very smart, this always confused me - she saw something in me, I now understand what that is but at the time I remember feeling like me...bright? ...never...!

\section{JB: What was your experience in the workplace as a dyslexic person?}

NJ: When I was looking for a role, I avoided looking for a role where they used an assessment centre, as I knew with dyslexia my written work would suffer from this scrutiny. My first job was in Rolls Royce in a psychology, human factors role. This was just an interview. I was always good verbally at explaining things. I was shocked I got the job! I was starting to realise that maybe I could achieve after all. I really enjoyed the work, but when it came to writing reports, I started to struggle. When I declared my dyslexia, I would have one person proofreading my work and then it might move to another for the same piece of work, and as people had different writing styles, they would correct each other's changes. I remember arriving at work and crying to myself, I was so stressed by the proofreading and never getting there. I applied for an internal HR role, this had been my plan I thought if I got in a company then I could move across, I got this role and I was so relived as I was very stressed by this point with the proofreading. The team were always kind when I said I had dyslexia - they were doing their best, but I don't think they realised how hard it was on me.

\section{JB: Why did you set up Lexxic?}

NJ: Why is a great question! I had so many business ideas, for example, a consumer psychologist company, coaching, but I knew from some entrepreneurial events I had been to that I could not spread myself so thinly. So, I just went with where my heart was, where the passion was, to help people who are similar to me to avoid what I had struggled with because I did not want people to go through the same challenges and emotional rollercoaster as myself. The biggest thing is if you can get someone to go from 'they can't do' to 'they can do' by teaching them the strategies this is such a great moment, the penny dropping, the light going on, because they will then start to see opportunity in the world rather than as a place that works against them. 
JB: What type of work do you do with employees in the companies?

NJ: We work with a range of companies providing diagnostic assessment for neurodiverse conditions (i.e. dyslexia, dyspraxia etc.). We provide reports where we identify types of adjustment that can support the employee in their role; the biggest behavioural change comes through the assistive technology and the one-to-one dyslexia/neurodiversity coaching. This is where you see the person really become empowered and see positive progress within the role. We also work with organisations on neurodiversity strategy, for example, organisations looking for coding skills are more likely to find a pool of these skills in certain neurodiverse profiles.

JB: What are the benefits to employees of your work?

NJ: In Lexxic, when you bring together a team of neurodiverse and nonneurodiverse individuals, you can see why differences add so much to the workforce. For example, the ADHD sales person with 100 ideas and energy to grow the business: the dyslexic psychologist sharing their own personal experience with someone who has had the same challenges to overcome for success; the autistic coder who can see patterns that no-one else can in the coding, but if you expect them to be the most sociable person in the team, this may not be the case. When you bring difference together, you thrive and grow through different perspectives and talents. A group of linear brains may never come up with the creative ideas, a group of bigger-picture brains may never get to the detail....or have too many ideas they don't see them through, but together we can create such an amazing environment of innovation and implementation. However, if people recruit people the same as themselves, they may never get to see this.

JB: What are the benefits to the companies from your interventions?

NJ: When people have dyslexia or neurodiverse interventions and start to understand how they learn, suddenly they can work with how they learn using more effective ways to help them achieve the end goal, rather than rereading to the point that it feels like your brain is going to explode. The more you understand how you work and what works for you, the more you can navigate the world of education and work and work out what types of roles and subjects suit who you are because you are unique and not the same as the person next to you.

JB: How is Lexxic developing as a company?

NJ: We are continuing to help people, to innovate and to develop our elearning strategies for adults to help as many people as possible become empowered from neurodiverse strategies to support them.

JB: What are the main insights that you have gained from your work?

NJ: The difference you can make for someone with dyslexia in a relatively short period with our strategies! How they can impact the person's confidence and self-belief is amazing.

JB: What opportunities and challenges lie ahead for Lexxic?

NJ: As the world of neurodiversity grows, we are looking to educate and continue to help more and more people through more innovative ways and tell the stories and share the experience to help other neurodiverse individuals thrive. 